\title{
Environmental Learning for Coping with Drought among Small Scale Farmers of Luangwa District, Zambia
}

\author{
Chipatu Lillian", Charles M. Namafe ${ }^{2}$ \\ The University of Zambia, School of Education, \\ Department of Language and Social Sciences Education, Lusaka, Zambia
}

\begin{abstract}
Environmental learning is learning about, in and for the environment. With recent recordings of changes in rainfall patterns, environmental learning can enhance rain fed agriculturalists with sound knowledge and skills needed to cope with or manage environmental hazards such as drought. Exploring environmental learning for coping with drought among small scale farmers of Zambia's Luangwa district constituted the aim of this study. The study was informed by a critical realism paradigm as well as situated learning and structural functional theories set within qualitative methodologies.
\end{abstract}

Keywords: Drought, Drought Coping, Environmental Learning, Small Scale Farmers

\section{INTRODUCTION}

Zambia has historically been affected by drought and flooding. The frequency, intensity and geographic distribution of such incidents have increased over the past two decades (Kalinda, 2014; Lekprichakul, 2008). Climate change projections outlined in the Zambia National Adaptation Programme of Action (NAPA) showed an increase in temperature and a change in rainfall patterns, leading to prolonged droughts, localized flooding and a shortened growing season in Zambia (Ministry of Tourism, Environment and Natural Resources (MTENR), 2007). As a result, Zambia experiences dearth at critical periods of the cropping calendars, resulting in severe decreases in crop yields. It is worth noting that agriculture is an important sector in Zambia and that 75 per cent of the population directly or indirectly depends on the sector ((Food and Agriculture Organisation (FAO) /World Food Programme (WFP), 2005). A vast majority of small scale farmers are heavily dependent on rain fed farming. Persistent occurrences of drought therefore, may entail serious risks for the livelihood of such rain-fed agriculturalists.

One of the districts in Zambia that is constantly hit by drought, and which has small scale farmers, is Luangwa District (Kamisa, 2008). Luangwa district is in Lusaka province and lies within a marginal area that is prone to both drought and floods in the rainy season (Luangwa District Council, 2007). Despite employing varieties of drought coping strategies, people of Luangwa District continued to be adversely affected by drought and floods, in terms of food in security and the general livelihood of the population. Some drought relief from the Zambian government and other organisations have been of good help, though it is not a sustainable solution and, hence, it is a common scenario for small scale farmers to call for help from the government (Luangwa District Council, 2007; Kamisa, 2008). Carter et al., (2006) noted that relief support from government and other organisations is unsustainable and a perfect vehicle for poverty perpetuity among small scale farmers. One issue that could be of a sustainable nature concerning drought coping among small- scale farmers of Luangwa District has to do with environmental learning.

Environmental learning pertaining to drought coping has not been examined by many scholars before and yet it enhances environmental knowledge which is key in contributing to important decisions concerning drought. Environmental learning about drought could play a vital role in helping small scale farmers live in harmony with nature, develop more environmentally benign strategies and consequently be able to efficiently cope with drought (World Commission on Environment and Development, 1987; Holdren, 1990; Kane, 1996; Goulder, 1999; IFAD, 2009). Environmental learning for drought coping is cardinal in behavioural and social change for adaptation. 


\subsection{Statement of the Problem}

Despite small scale farmers of Luangwa district using various drought coping strategies, they continue to experience negative drought impacts such as food insecurity. As a result, such farmers depend on relief food and various forms of help from the Zambian government (Kaminsa, 2008). The provision of drought relief to small scale farmers of Luangwa district has not helped much in the sense that the beneficiaries have shown increased vulnerability to future drought episodes by reducing their selfreliance and increasing dependence on government and donor organizations (Pulwarty et al., 2014). On the other hand, the nature of environmental learning of drought coping such farmers is not known. Lack of information on the nature of environmental learning of drought coping among small- scale farmers of Luangwa district means that decision makers and policy makers may be ill-equipped to come up with appropriate educational measures to enhance their capacity to cope with drought. This situation could perpetuate vulnerability to drought hazard among such farmers. In addition, the said situation may impede the realisation of Zambia's Sixth National Development Plan (2013 - 2016) whose vision is to have "a competitive and diversified agricultural sector driven by equitable and sustainable agricultural development" (Government of the Republic of Zambia, (GRZ) 2013).

In order to address the above problem, a study was undertaken in the year 2016 forming the subject of this paper.

\subsection{Aim}

The study aimed to examine environmental learning related to drought coping strategies so to determine its appropriateness to drought coping

\subsection{Objective}

In order to address this aim, the specific objective of the study was to explore the nature of environmental learning pertaining to drought coping strategies found among small scale farmers of Luangwa District.

\section{LiteratURE REVIEW}

Drought represents one of the most reoccurring hazards that have resulted into starvation and famine in many parts of the world (Haile, 2005). At the time of conducting this study in the year 2016, many countries of Southern Africa (i.e. Zimbabwe, Malawi, Botswana, Swaziland and Namibia were also experiencing drought). The review of literature brought out important points. Some of the points were that small scale farmers' learning was mainly served through the extension service (Makasa, 2002; Mbashili, 2007). Another key finding was that small scale farmers' learning was basically on generally farming practices (Chaudhury et al., 2011; Suzuku et al., 2002; World Food Programme, 2013) and crop marketing (Mboozi 2000) among others. This was the situation despite small scale farmers' exposure to different environment issues that may demand situated form of learning.

\section{Methodology}

\subsection{Design and Sampling}

The study was conducted in Luangwa District. The study adopted a qualitative approach using holistic case design. Qualitative research is useful in the study of educational settings and processes (Denzin and Lincoln, 2003). Furthermore, purposive samplings were adopted to select the participants. Purposive sampling involves the researcher making a conscious decision about which individuals and which research sites would best provide the desired information (Bryman, 2008). Data saturation was employed in getting information from the small scale farmers. A total number of 6 small scale farmers from villages such as Katope were interviewed to determine whether there was need to conduct more than 1 focus group discussion. It was discovered that these interviewed gave similar information to what the researcher got from the focus group discussion hence there was no need for more interviews with the small scale farmers. Thus the sample size consist 7 small scale farmers from 7 villages, 1 Disaster Management Officer, 1 Agriculture Supervisor and 2 Planning Officers Extension Officer. Table 1 shows the sample size and the sampling techniques and types employed in this study. Sample size and sampling techniques are shown in table 1 below. 
Environmental Learning for Coping with Drought among Small Scale Farmers of Luangwa District, Zambia

Table1. No. of Participant and Sampling techniques used in this Case Study

\begin{tabular}{|c|c|c|c|}
\hline Participants & No. of Participants & Sampling Techniques & $\begin{array}{c}\text { Sampling Technique } \\
\text { Types }\end{array}$ \\
\hline Ministry of Agriculture & 2 & Purposive and Snowball & Expert and Linear \\
\hline $\begin{array}{c}\text { Ministry of Local } \\
\text { Government and Housing }\end{array}$ & 1 & Snowball & Linear \\
\hline Disaster Management Unit & 1 & Purposive & Expert \\
\hline Child Fund (NGO) & 1 & Snowball & Linear \\
\hline Small Scale Farmers & 7 & Purposive & Homogenous \\
\hline
\end{tabular}

Source: Field Data, 2016

\subsection{Instrument}

A variety of data collection instruments are available under the case study approach (Yin, 2003) and thus primary data was collected through semi-structured interview guide, focus group discussion and observation. Interviews were done with experts, while getting information from the small scale farmers was done through a focus group discussion. Furthermore, secondary data was collected through reading and reviewing different documents related to the subject proposed. Sources included books, articles, journals and reports (Leedy and Ormord, 2001).

Table2. Summary of the research methods

\begin{tabular}{|c|c|c|c|}
\hline Method & Instrument & Data Type & Approach \\
\hline Interviews & $\begin{array}{c}\text { Semi Structured } \\
\text { Interview }\end{array}$ & Qualitative & $\begin{array}{c}\text { Interpretive } \\
\text { (emergent findings) }\end{array}$ \\
\hline Focus Group Discussion & $\begin{array}{c}\text { Focus Group Discussion } \\
\text { Question Guide }\end{array}$ & Qualitative & $\begin{array}{c}\text { Interpretive } \\
\text { (emergent findings) }\end{array}$ \\
\hline Observation & Observation Guide & Qualitative & $\begin{array}{c}\text { Interpretive } \\
\text { (emergent findings) }\end{array}$ \\
\hline
\end{tabular}

Source: Field Data, 2016

\subsection{Data Analysis}

Data analysis was done through thematic analysis. Thematic analysis falls under the type of data analysis that is not tied to any theoretical or epistemological positions (Boyatzis, 1998). Thematic analysis is a method for identifying, analysing, and reporting patterns (themes) within data (Braun and Clarke, 2006).The process of analysis is indicated in figure one on the next page.

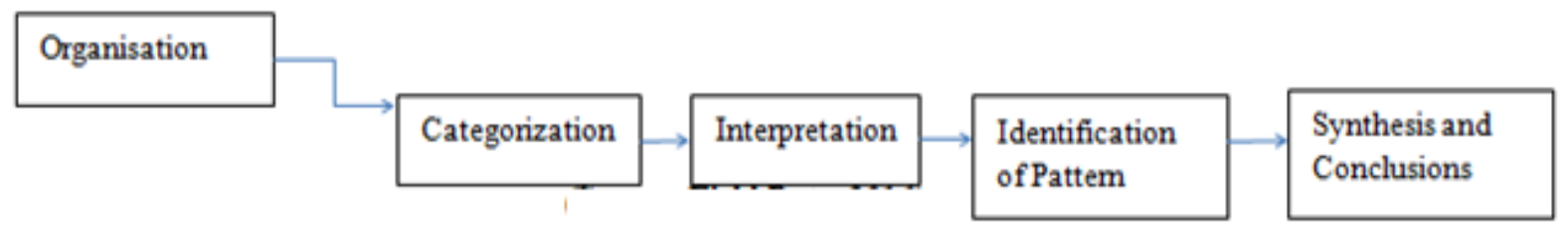

Figure1. Process of data analysis

Source: Field Data, 2016.

\subsection{Data Validation and Trustworthiness}

Methodological triangulation and mirror data triangulation were used to validate the data. Methodological triangulation is the use of two or more research methods in one study at the level of data collection or design (Taylor, Kermode, and Roberts, 2007). This was achieved by the use of interviews, observations and focus group discussion. Mirror Data triangulation is a validation technique in which part or whole of the processed data from the field is taken back to that same field it was originally sourced, in order to have it screened by research participants who confirm whether or not it reflects information in a way that preserves much of its original quality after undergoing analytical processing (Lotz-Sisitka, 2011). This was achieved through organizing information-sharing discussions with stakeholders who provided data related to the study. For stakeholders who could not be accessed easily, information was sent to them electronically and feedback was received from them electronically. 


\section{FINDINGS AND DISCUSSIONS}

\section{Small Scale Farmers' Educators}

Small scale farmers indicated that only Extension Officers from the Ministry of Agriculture were directly involved in educating them on good farming practices. Significantly, there were many other studies that supported this finding including the following; (Chaudhury et al, 2011, MAFF, 2000b, Makasa 2002, Mbashili 2007, Mbozi, 2000, Sutherland 1988). However, this finding was inconsistent with the educators. They asserted that extension officers and an NGO (Child Fund) were involved in educating small scale farmers of Luangwa district. This discrepancy could be attributed to lack of much interaction between the small scale farmers and the educationists. Whatever the case, educationists and the small scale farmers of Luangwa district should be able to interact and work together towards effective drought coping.

\section{Approached Used by Educators}

It was also established that an Integrated Agricultural Approach was used in educating small scale farmers. However, Integrated Agriculture Approach focused on good farming practices in general and not specifically on drought coping. Although a claim was made that a small component on drought was covered in this Integrated Agriculture Approach, the study established that learning for drought coping had been superficial. Without doubt, learning about general farming practices was good. However, environmental learning among the small scale farmers of Luangwa district would be more viable if learning was specific to drought since Luangwa district was a drought prone area and drought was the greatest threat to the wellbeing of the small scale farmers of Luangwa district. Thus, effective environmental learning for drought coping must embrace learning activities that are responsive to local environmental context and issues. Furthermore, the use of an Agriculture Integrated Approach to drought coping was inconsistent with Lave and Wengers' (1991) model of learning presented in situated learning theory. Lave and Wenger (1991) argued that effective learning involves knowledge situated in a relevant or authentic manner. Learning must be problem driven, concrete and contextual within the prevailing situation. Knowledge needs to be presented in an authentic context, i.e., locales and applications that would normally involve that knowledge (McLellan, 1995).

\section{Topics Covered}

It was also discovered that an Integrated Agriculture Approach was used in educating small scale farmers of Luangwa district. Under the Integrated Agriculture Approach, participants A and D avowed that small scale farmers learnt crop production, tree planting, livestock farming and fish farming. This was confirmed by the remark below:

small scale farmers learn crop production, tree planting, livestock farming and fish farming. Under crop production, small scale farmers learn on conservation farming (minimum tillage), planting of early maturing seeds, growing of drought resistant crops and intercropping. For intercropping, crops that we encouraged are cowpeas, pumpkins, maize, sorghum, sun hump and groundnuts. In Chitope and Katondwe areas of Luangwa District, small scale farmers are trained in good management of bananas. On tree planting, small scale learn on management of acacia tree. Learning on livestock includes knowledge on rearing of cattle, goats, guinea fowls and chickens. In addition, small scale farmers are trained in management of fish and fish ponds. Tilapia fish farming is generally encouraged among the small scale farmers. Training of the small scale farmers in various farming activities is at camp level and there are about nine camps in Luangwa district, (Participant A, 30 ${ }^{\text {th }}$ March, 2016, Interview).

However, small scale farmers indicated that only moisture conservation was covered by both extension officers and JAICA. This disparity on topics covered under integrated approach could be due to the fact that all indicated topics by the educators were not yet implemented according to plan. The situation was even more complex as there was no evidence of learning/teaching materials to support the educators' assertions. This finding also cast a dark shadow on the nature of environmental learning for drought coping as learning and teaching materials are an integral part of effective learning.

\section{Competences for Drought Coping}

The study revealed that small scale farmers learnt drought coping strategies from their parents. This was confirmed by the remark below: 
tiziwa mokhalira mu chilala chifukwa makolo athu anatiphuuzisa mokhalila, (Participant $3,31^{\text {st }}$ March, 2016, FGD). (We learn drought coping through information that is passed on from parents).

All the other participants unanimously stated in agreement that they learnt drought coping strategies from their parents. Teaching/learning methods used for drought coping here included observations, guided and correction. This correlated well with Mbozi (2000) who showed that among the small scale farmers of Southern Province of Zambia, observation, guided and correction approach comprised the teaching methods. The study also showed that traditional drought responses were the main coping strategies utilised by the small scale farmers of Luangwa district. This could be that the content covered under integrated agriculture was not situated to drought coping. This situation had a potential of making learning to be a disjointed process whereby, making it impossible for small scale farmers to isolate components which could be helpful for drought coping. Further, there was a possibility that the educators did not link traditional ways of drought coping to modern knowledge as covered in the integrated approach. Ultimately, this made it hard for the small scale farmers of Luangwa district to negotiate and integrate traditional knowledge with new knowledge hence holding on to traditional coping strategies. Such a scenario calls for an introduction of environmental learning for drought coping rather than an integrated agriculture approach that merely covers good farming practices. Environmental learning approach for drought coping would require educators to foster acquisition of new knowledge and practices from other knowledge systems (modern scientific knowledge) while enhancing traditional knowledge and skills for drought coping. Traditional knowledge cannot be abandoned completely because it is situated within an ever changing local environment (Sikana, 1994) and still has the propensity of enhancing agricultural development among the small scale farmers (Chambers 1997; Roling, 1994). Therefore, a combination of other knowledge systems (modern scientific knowledge) and traditional scientific knowledge may make learning relevant, at the same time, help small scale farmers of Luangwa district develop and apply innovative approaches to drought coping. Tackling environmental issues such as drought through environmental learning demand for much learning from experiences that may be different from already existing ones, that is, there is an element of social innovation (CARE, 2010), but at the same time embracing traditional knowledge that provides ways of teaching and learning locally relevant knowledge and skills. Analogously, modern science should exist side by side with alternative sciences (traditional science) (Visvanathan, 2006). Environmental learning for drought coping among small scale farmers of Luangwa district could be helpful if learning stages as articulated by Mukute (2010) are implemented. The stages include:

- Scaffolding; using traditional ways of knowing (knowledge and skills) as a spring board, small scale farmers would move to the next level of understanding drought through other knowledge systems (modern scientific knowledge) with the assistance of an educator who leads the small scale farmers to mastery.

- Cultural interpretation of learning; where an educator would exchange ideas with the small scale farmers to help them make connections between traditional knowledge and other knowledge systems (modern scientific knowledge). Educators must be in a position to assist learners move from situated everyday understandings to scientific concepts (Edwards, 2005)

- Collectivist interpretation of learning; where small scale farmers with different experiences and perspectives work together on drought coping and strive together to develop new knowledge or tools for effective drought coping.

This researcher thus argues that since our knowledge of reality may be educators should ensure that modern scientific knowledge dialogues and negotiates with traditional knowledge on drought coping to create possibilities for efficient drought coping among the small scale farmers of Luangwa district.

\section{Mode of Teaching}

Educators and the small scale farmers of Luangwa district agreed that workshops and demonstrations were used as teaching methods in the small scale farmers' learning process. Similarly, the findings of this study confirmed the earlier findings by Makasa (2002), who stated that workshops and demonstration were used as teaching methods among small scale farmers of Mambwa District of Central Province of Zambia. Moreover, small scale farmers of Luangwa district also indicated that 
Agriculture Extension Officers gave them (small scale farmers) an opportunity to air out their views during workshops and demonstrations. This discovery was inconsistency with Mbozi's (2000) and Worth's (2006) findings. Mbozi, (2000) and Worth (2006) postulated that the agricultural extension in Zambia, operated through a linear mode of technology transfer, conveying to farmers the latest technologies to improve production, with success measured by the rate of adoption without giving farmers a voice in the whole process. The key assumption in the above linear mode of agriculture extension services delivery was that scientists did the research and design, extension workers disseminated and farmers consumed (Leeuwis, 2004). Some of the limitations of the linear mode of agriculture extension services comprises supply-driven by scientists; a lack of consideration of local knowledge, diversity, sustainability and farmer needs; and farmer inability to afford the kind of technologies being promoted (Mutuke, 2010). However, findings on giving small scale farmers a voice showed some form of change in the linear mode of extension services as used in Luangwa district. In another study, Mutuke, (2010) also noted these changes when he stated that some changes had occurred in the way extension services were carried out over the past decades. Whatever the case, it remains a well-known fact that learners have different learning styles, preferences and ways of expressing knowledge and skills (Thompson-Schill, Kraemer, Rosenberg, 2009). Thus the use of varied strategies, techniques and teaching methods would be more beneficial than engaging small scale farmers in only workshops and demonstrations. By being knowledgeable that small scale farmers have different learning preferences, educators can learn to efficiently communicate in ways that small scale farmers can understand .Thus diverse strategies, techniques and teaching methods may ensure that small scale farmers have an equal opportunity to learn, share and take responsible action based on new information learnt. Educators should therefore consider diversity among learners if they are to help them retain information and strengthen understanding (Crawford, 2010).

\section{Conclusion}

The study brought out important points concerning environmental learning for drought coping and drought coping in Luangwa District of Lusaka Province of Zambia. The study established that Extension Officers from the Ministry of Agriculture and officers from Child Fund utilised an agriculture integrated approach in educating small scale farmers. Further, the study established that an integrated approach to agriculture focused on general farming practices and not specifically on drought coping. It was however discovered that traditional drought coping strategies employed by small scale farmers of Luangwa district were ineffectual. Consequently, small scale farmers resorted to food begging and relief food from the government and other well - wishers. With regard to the above situation, it can be conclusively stated that environmental learning for drought coping among small scale farmers of Luangwa district was superficial in nature.

\section{RECOMMENDATIONS}

In order to enforce environmental learning for drought coping among the small scale farmers of Luangwa district, the following recommendations may have to be taken into consideration:

- The findings of this study showed that general farming practices were taught to small scale farmers. Arising from this, the content should be revisited so that more on drought coping is incorporated.

- The findings indicated that small scale farmers utilised mainly traditional coping strategies. In view of such findings, there is need to incorporate different ways of knowing into curricula to bring together participatory and other learning approaches for small scale farmers. Environmental learning for drought coping should be a melting point of different knowledge systems and sources such as traditional and modern science. This will enhance localization of the curriculum and make learning relevant.

- Another finding was that, there were no visible teaching materials in place. There is need therefore to embark on educational material development.

\section{REFERENCES}

Bryman, A. (2008). Social Research Methods. New York: Oxford University.

Carter, M. R., Little, P. D., Mogues, T., and Negatu, W. (2006). Shocks, Sensitivity and Resilience: Tracking the Economic Impacts of Environmental Disaster on Assets in Ethiopia and Honduras. DSGD Discussion Paper No. 32. International Food Policy Research Institute (IFPRI). Washington D.C. Retrieved January 12, 2013, from http://www.ifpri.org/sites/default/files/ publications/dsgdp32.pdf 
Environmental Learning for Coping with Drought among Small Scale Farmers of Luangwa District, Zambia

Chaudhury M, Ajayi OC, Hellin J, Neufeldt H. (2011). Climate change adaptation and social protection in agroforestry systems: enhancing adaptive capacity and minimizing risk of drought in Zambia and Honduras. ICRAF Working Paper No. 137. Nairobi: World Agroforestry Centre. http://dx.doi.org/10.5716/WP11269.PDF

Crawford, D. (2010).The Role of Aging in Adult Learning: Implications for Instructions

Denzin, N. and Lincoln, Y. (2003), "The Discipline and Practice of Qualitative Research", in Denzin, N. and Lincoln, Y. (eds.) Collecting and Interpreting Qualitative Materials, 2nd ed, SAGE Publications, Inc., California, pp. 1-45.

FAO/WFP. (2005), Special Report: FAO/WFP Crop and Food Supply Assessment Mission to Zambia, June 24, 2005, Rome: World Food Programme, Food and Agriculture Organization of the United Nations.

JAICAF (2008). The Maize in Zambia and Malawi, Japanese Association for International Collaboration of Agriculture and Forestry. March 2008.

Kalinda, T. (2014). Multiple Shocks and Risk Management Strategies among Rural

Households in Zambia's Mazabuka District: Journal of Sustainable Development; Vol. 7, No. 5; 2014 ISSN 1913-9063 E-ISSN 1913-9071: Published by Canadian Center of Science and Education.

Kamisa, L, (2008). Luangwa District Situation Analysis. Government of the Republic of Zambia.

Leedy, P.D. and Ormrod J.E. (2001). Practical Research: Planning and Design. New Jersey: Merill Prentice Hall.

Lekprichakul, T. (2008). Impact of 2004/2005 Drought on Zambia's Agricultural Production: Preliminary Results. Vulnerability and Resilience of Social-Ecological Systems, Research Institute for Humanity and Nature.

Lotz-Sisitka, H. (2011). National case study - Teacher professional development with an education for sustainable development focus in South Africa: Development of a network, curriculum framework and resources for teacher education. Southern African Journal of Environmental Education, 28, 30-65

Makasa, V., (2002).Participation of Smallholder Farmers in Agricultural Extension Service in Zambia: An Evaluation of the Ministry -operated Extension Service in Mambwa District of Central Province, Unpublished dissertation, Department of Agricultural Economic, University of Zambia

Mukute, M. 2010. Exploring and Expanding Learning in Sustainable Agriculture Workplace Context. Unpublished PhD thesis, Rhodes University, South Africa.

World Bank. (1986). Report and Recommendation of the President of IDA to the Executive Directors on a proposal Credit to the Republic of Zambia for an Agricultural Research and Extension Service Project. Report No. P - 4136 - ZA. Washington, D.C

\section{AUTHORS' BIOGRAPHY}

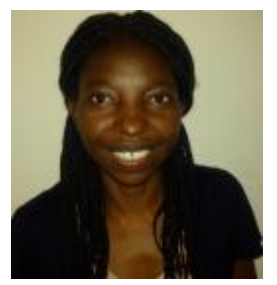

Chipatu. $\mathbf{L}$ is currently a special research fellow at the University of Zambia. Her research interests are environmental learning and Natural Hazards.

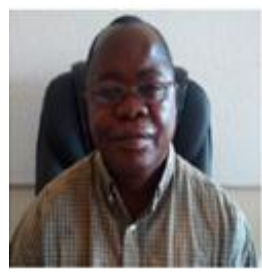

Charles M. Namafe is currently Associate Professor of Environmental Education at the University of Zambia in the School of Education. His research interests are water studies, conflict and its resolution as well as issues to do with culture. 